\title{
SUBSIDIOS, PERMISOS Y CONDICIONES: LA DOCTRINA DE LAS CONDICIONES INCONSTITUCIONALES EN ESTADOS UNIDOS Y SU APLICACIÓN EN CHILE
}

\author{
SUBSIDIES, AUTHORIZATIONS AND CONDITIONS: THE \\ UNCONSTITUTIONAL CONDITION DOCTRINE IN THE UNITED \\ STATES AND ITS APPLICATION IN CHILE
}

\author{
Sebastián Soto VeLASCo*
}

\begin{abstract}
RESUMEN: Este trabajo analiza la doctrina de las condiciones inconstitucionales en Estados Unidos y sus posibles implicancias en el ordenamiento nacional. La doctrina, en virtud de la cual sería inconstitucional que el Estado condicionara la recepción de fondos públicos a la renuncia de derechos fundamentales por parte del receptor, ha dado pie a una interesante jurisprudencia y discusión académica en los Estados Unidos que a continuación se analiza. Posteriormente, se presentan algunos antecedentes en nuestro derecho contenidos especialmente en sentencias del Tribunal Constitucional con miras a encontrar fundamentos para una articulación de esta doctrina en Chile.
\end{abstract}

Palabras clave: condiciones inconstitucionales, subsidios, permisos.

ABSTRACT: This document refers to the unconstitutional condition doctrine in the United States and its possible application in our legal system. The doctrine states that the Constitution does not allow the government to require someone to surrender a constitutional right as a condition to receive some governmental benefit. The following pages analyze this contended doctrine considering the current constitutional debate and the case law in the United States. Then, the article presents some decisions of the Chilean Constitutional Court in order to find the foundations of such doctrine in Chile.

Key words: unconstitutional condition, subsidies, authorizations.

\section{INTRODUCCIÓN}

En la sociedad moderna, el Estado ha asumido roles en los que antiguamente no solía estar involucrado. Sectores como la educación, la salud, la cultura o la regulación urbana son nuevas áreas en que la potestad gubernamental ha ingresado con diversos objetivos. Una de las formas que el Estado ha utilizado para ingresar en estas áreas es a

\footnotetext{
* Licenciado en Ciencias Jurídicas Pontificia Universidad Católica de Chile y Máster en Derecho de la Universidad de Columbia, Nueva York. Correo electrónico: ssoto@lyd.org. Actualmente se desempeña como Director del Programa Legislativo de Libertad y Desarrollo y como Profesor en la Facultad de Derecho de la Universidad Católica. Una versión preliminar de este documento fue presentada por el autor en el Congreso Estudiantil de Derecho y Teoría Constitucional de la Universidad de Chile (2007). Agradezco los comentarios que hicieron en esa oportunidad Pablo Ruiz-Tagle y otros asistentes. Agradezco también los aportes de Axel Buchheister a un texto posterior.
} 
través de los subsidios estatales, es decir, a través de transferencias directas o indirectas de dinero público a individuos o entidades privadas. En este panorama, es común que las asignaciones presupuestarias o la transferencia de recursos queden sujetas a condiciones que deben ser cumplidas por los receptores. Ejemplos de esta tendencia son los programas de transferencia condicionada de dinero, muy comunes en Latinoamérica, que entregan fondos públicos a familias pobres bajo ciertas condiciones y obligaciones que deben cumplir los receptores ${ }^{1}$.

Así como estos programas, muchos otros también condicionan la recepción de fondos públicos. En Estados Unidos, el hecho que estas condiciones pueden limitar indebidamente derechos constitucionales ha generado una discusión académica y jurisprudencial en torno a lo que ha venido a conocerse como la doctrina de las condiciones inconstitucionales. En virtud de esta doctrina, el Estado no podría exigir que el receptor de un beneficio público renuncie a alguno de sus derechos fundamentales. Esto, aun cuando el Estado mismo no está en la obligación de conceder ese beneficio.

En este trabajo estudiaremos los orígenes, perspectivas y casos emblemáticos donde la doctrina de las condiciones inconstitucionales ha estado en juego. Analizaremos la opinión de los académicos y las dudas en cuanto a la verdadera existencia de tal doctrina. Posteriormente, volveremos la vista a nuestro país con miras a encontrar los primeros antecedentes o espacios donde una doctrina como la señalada podría tener aplicación.

\section{LA DOCTRINA DE LAS CONDICIONES INCONSTITUCIONALES}

\subsection{ANTECEDENTES}

Un importante caso en la jurisprudencia de la Corte Suprema de Estados Unidos es United States v. Butler ${ }^{2}$ que zanja una antigua discusión respecto al modo en que debía realizarse el gasto fiscal del gobierno federal. La polémica se remontaba a discrepancias entre dos autores de la Constitución: Madison y Hamilton. Mientras el primero sostenía que el Congreso solo podía asignar recursos para el cumplimiento de las facultades que la Constitución enumeraba expresamente, el segundo consideraba que el Congreso tenía amplias facultades en la asignación de los recursos públicos con una sola limitante: estos debían ser destinados al bienestar general de los Estados Unidos. En Butler, la Corte Suprema acoge la doctrina de Hamilton y, en consecuencia, le reconoce al Congreso amplias potestades para gastar los fondos fiscales. Acto seguido, la misma Corte se pregunta si el Congreso está sometido a alguna restricción en la asignación de dichos dineros. La respuesta es afirmativa y, entre otros fundamentos, recuerda que el mismo Hamilton pensaba que el propósito del gasto debía ser general y no local y que Monroe, otro de los que apoyaban la tesis de Hamilton, había escrito: “ $¿$ Tiene el Congreso un derecho a asignar los fondos fiscales para cualquier propósito según su propia voluntad o placer? Ciertamente no lo tiene" ${ }^{3}$. Sin embargo, la Corte no va más allá en

\footnotetext{
${ }^{1}$ RaWlings y Rubio (2003) evalúa estos programas en Brasil, México, Honduras, Jamaica y Nicaragua.

2 United States $v$. Butler (1936).

${ }^{3}$ RAWLingS y RUBio (2003) p. 67.
} 
las posibles limitantes de las atribuciones presupuestarias del Congreso y reconoce, simplemente, la existencia de limitaciones teóricas.

Una de estas limitaciones es la que despierta mayor interés para esta investigación. Se trata de la que emana de la llamada doctrina de las condiciones inconstitucionales.

La doctrina de las condiciones inconstitucionales se inserta en la práctica, ya habitual, de beneficiar con la entrega de recursos públicos a determinadas personas, gobiernos locales u otras sociedades intermedias. En muchas ocasiones, estas transferencias requieren que los beneficiarios reúnan ciertas condiciones para poder acceder al beneficio. Estas condiciones pueden tener diversos objetivos: algunas buscan el cumplimiento de ciertos requisitos o estándares mínimos. Otras, en cambio, exigen a los beneficiarios la renuncia a ciertos derechos fundamentales. En determinadas circunstancias, y en virtud de la doctrina de las condiciones inconstitucionales, estas últimas condiciones pueden ser calificadas de inconstitucionales y, en consecuencia, ser inaplicables. En otras palabras, dicha doctrina prohíbe que las asignaciones presupuestarias que realiza el Congreso estén sujetas a condiciones que importan la renuncia de derechos fundamentales ${ }^{4}$.

Este planteamiento, que resulta en principio atractivo, se complica al momento de entrar a analizar los casos concretos. En efecto, en Estados Unidos no es posible decir que se ha alcanzado un consenso en el contenido, ámbito y perspectivas de la doctrina. Tanto así que mientras una serie de académicos destacan la importancia de la doctrina, otros tantos, igualmente importantes, afirman que tal doctrina no existe.

En las próximas páginas analizaremos brevemente la evolución de la doctrina, los casos relevantes, las dudas que esta genera y los criterios planteados por algunos académicos para dar mayor consistencia a la doctrina.

\subsection{Historia: PRIMERAS APROXIMACIONES}

Los primeros casos de condiciones inconstitucionales se encuentran en los esfuerzos de ciertos estados en EE.UU. destinados a prohibir que corporaciones extranjeras que tenían inversiones dentro del Estado, recurrieran a cortes federales. De acuerdo con uno de los primeros trabajos escritos sobre el tema, el caso de Insurance Co. v. Morse es la fuente de la doctrina aunque en este nunca se utiliza el término condición inconstitucional $^{6}$. En este caso, la Corte Suprema invalidó una ley que requería que las sociedades extranjeras consintieran en no llevar sus controversias a sede federal como requisito para ser admitido dentro de las fronteras del Estado. En este y otros casos, la Corte analizó principalmente si los estados estaban o no autorizados para negar el ingreso de corporaciones extranjeras. Si lo estaban, parecía natural que también estuvieran autorizados para condicionar su admisión. Pero, como señala Merrill, "el uso del poder negociador de los

\footnotetext{
${ }^{4}$ Con razón, Hayek ha escrito que "la administración de los recursos encomendada al gobierno con el fin de prestar servicios a los ciudadanos se refiere, por naturaleza, a problemas de corto plazo, y debe atender a la satisfacción de necesidades particulares, pudiendo disponer no del ciudadano privado sino de los recursos puestos explícitamente bajo su control'. HAYEK (2006) p. 490.

5 Insurance Company v. Morse (1874).

${ }^{6}$ Merrill (1929) p. 879.
} 
estados con miras a desincentivar o restringir recursos a las cortes federales podía ser correctamente considerado tan inconsistente con el funcionamiento del sistema de gobierno establecido por la Constitución de Estados Unidos como para ser prohibido por dicho documento"7.

Casos posteriores expandieron el ámbito de esta primera aproximación. La doctrina empezó a ser utilizada por compañías extranjeras para evitar intentos de forzarlas a renunciar a cualquier derecho constitucional como condición para ser admitidas en los estados.

Sin embargo, en estos primeros años la doctrina no solo tuvo límites difusos sino que también una fuerte oposición. Quien planteó la más dura crítica fue el juez Holmes $^{8}$ quien denunció "la falacia que implica hablar de condiciones inconstitucionales. (...) Confieso mi inhabilidad -continúa- para entender cómo una condición puede ser inconstitucional en casos en que el Estado tiene un poder absoluto y arbitrario" " Holmes es también el autor de un famoso fallo que, resolviendo un caso en el que se había despedido a un oficial de policía por su posición política, sentenció: "el recurrente puede tener un derecho reconocido en la Constitución a hablar de política, pero no tiene un derecho reconocido en la Constitución a ser un policía (...) El recurrente no puede alegar, pues tomó el empleo en los términos que le fue ofrecido"10. En otras palabras, reconoce Holmes, el policía puede ver condicionada su mantención en un oficio público a la exigencia de renunciar a su derecho a expresarse libremente ${ }^{11}$.

A pesar de las críticas y fallos adversos, la doctrina mantuvo su vigencia y, con la llegada del New Deal, adquiere nueva fuerza, cambiando su foco desde asuntos corporativos a los derechos individuales.

\subsection{Desde EL NEW DEAL HASTA NUESTROS DÍAS: DERECHOS FUNDAMENTALES Y FEDERALISMO \\ El New Deal dio paso en Estados Unidos a un período de crecimiento del aparato} estatal y de aumento del gasto público en diversas áreas de la vida del país. Con más dinero para distribuir y nuevas funciones que cumplir, la doctrina de las condiciones inconstitucionales empezó a ocupar un nuevo puesto. Como destaca Seth Kreimer, una vez que el gobierno se involucra profundamente en la vida económica y social de sus ciudadanos "el Estado está en posición de manipularlos tanto demostrándoles generosi-

\footnotetext{
7 Merrill (1929) p. 881.

8 Oliver Wendell Holmes fue juez de la Corte Suprema de Estados Unidos entre 1902 y 1932. Ampliamente reconocido como uno de los más influyentes jueces en la historia de Estados Unidos y como uno de los principales exponentes del Common-Law.

9 Western Union Telegraph Co. v. Kansas (1909) p. 53.

10 McAuliffe v. Mayor of New Bedford (1892) p. 518.

11 Nuestro Tribunal Constitucional también ha considerado que las personas que ejercen este tipo de labores se encuentra sometido a una relación de "sujeción especial" que admitiría, por ejemplo, un trato especial en la descripción típica que se hace de los delitos que pudieran cometer en el ejercicio de sus funciones. Ver Sentencias del Tribunal Constitucional Roles No 468 (2006) y 559 (2007). Para un resultado diverso ver Rol No 781 (2007). Con todo, en estos casos no se sigue la lógica del juez Holmes sino que se analiza el asunto desde la perspectiva del principio de tipicidad de la ley penal.
} 
dad como amenazándolos con prisión" ${ }^{12}$. La doctrina de las condiciones inconstitucionales, por lo tanto, empezó a ser usada como una útil limitante a esta discreción gubernamental.

Desde entonces, algunos casos han alcanzado la Corte Suprema alegando que el Estado está condicionando indebidamente la recepción de un beneficio o el ejercicio de un derecho fundamental. Las áreas en que se ha dado esta discusión son variadas y se vinculan, entre otras, con la primera enmienda de la Constitución de Estados Unidos, con el derecho de propiedad, con el federalismo ${ }^{13}$ y las reglas que rigen el proceso penal y la aplicación de las penas ${ }^{14}$. A continuación trataremos algunos casos con mayor profundidad vinculados con las dos primeras áreas mencionadas.

\section{i. La doctrina de las Condiciones Inconstitucionales y la Primera Enmienda}

La primera enmienda ${ }^{15}$ en el derecho estadounidense envuelve una serie de derechos y libertades que otros ordenamientos tratan individualmente. Tal es el caso del derecho a la privacidad sobre la base del cual la Corte Suprema, en el famoso caso Roe $v$. Wade, reconoció que el aborto no podía ser prohibido por tratarse de una materia que correspondía a la esfera privada de las mujeres. Más allá de la controversia que hasta el día de hoy sigue generando esta decisión ${ }^{16}$, lo cierto es que sentencias posteriores han reconocido y protegido el así denominado derecho a elegir abortar por parte de las mujeres ${ }^{17}$.

12 Kreimer (1984) p. 1396.

13 El caso más importante que vincula la doctrina de las condiciones inconstitucionales y el federalismo es South Dakota v. Dole (1987). En 1984 el Congreso Federal aprobó una ley que retenía el 5\% de los aportes federales a los fondos en infraestructura vial en aquellos estados en los que la edad para comprar alcohol fuera inferior a 21 años. En el Estado de South Dakota la edad era de 19 y, en consecuencia, debía renunciar a ese porcentaje de recursos. South Dakota alegó ante la Corte Suprema que la norma en cuestión violaba los límites que la Constitución imponía al gobierno federal para gastar los dineros públicos. La Corte Suprema rechazó el reclamo y creó un estándar para determinar cuándo las condiciones del gasto superaban los límites constitucionales.

${ }^{14}$ En derecho procesal penal de Estados Unidos es común que el fiscal y la defensa, a cambio de una declaración de culpabilidad en ciertos delitos, negocien la renuncia a ciertos derechos fundamentales reconocidos constitucionalmente. Como lo ha expresado Mazzone "La Corte Suprema ha reconocido que la defensa de un criminal puede prescindir de ciertas protecciones constitucionales, incluidos el derecho garantizado en la cuarta enmienda a no ser sometido a registros y confiscaciones no razonables, el garantizado en la quinta enmienda en contra de la autoincriminación, y los derechos a un jurado, al careo con testigos y a asistencia jurídica de la sexta enmienda. En efecto, estas protecciones penales son rutinariamente renunciadas a cambio de reducciones en las sentencias, renuncias a presentar nuevos cargos u otros beneficios, cuando la defensa se declara culpable (plea agreement)". MAZZONE (2002-2003) p. 801.

${ }^{15}$ La primera enmienda dispone que "El Congreso no hará ley alguna por la que adopte una religión como oficial del Estado o se prohíba practicarla libremente, o que coarte la libertad de palabra o de imprenta, o el derecho del pueblo para reunirse pacíficamente y para pedir al gobierno la reparación de agravios". Traducción tomada de http://usinfo.state.gov/espanol/constes.htm. Visitado por última vez el 1 de septiembre de 2008 .

16 Ver el último caso al respecto: Gonzales v. Carhart et al. (2007).

17 Un completo análisis constitucional del aborto en Estados Unidos en SUlLivan y GUNTHER (2004) pp. 558-587. 
En este contexto se incorpora la primera sentencia que analizaremos, Rust $v$. Sullivan ${ }^{18}$, que vincula la doctrina de las condiciones inconstitucionales y el derecho de las mujeres para realizarse un aborto. Esta decisión es la que diversos libros de casos utilizan para introducir la tensión inherente que tal doctrina genera entre el poder estatal de asignar fondos públicos y las libertades civiles ${ }^{19}$.

En este caso, la ley de Servicios Públicos de Salud disponía que ningún fondo público federal podía ser usado en programas en los cuales el aborto era utilizado como un método de planificación familiar. El Departamento de Salud y Recursos Humanos de Estados Unidos, con miras a implementar la ley, aprobó una regulación que fue llevada ante los tribunales alegando la inconstitucionalidad. Los recurrentes reclamaban, entre otras cosas, que la regulación no era válida pues imponía una condición que limitaba la privacidad consagrada en la primera enmienda.

La Corte falló que el gobierno no estaba negando ningún beneficio a nadie, "pero está, en cambio, simplemente insistiendo que ciertos fondos públicos sean gastados para los propósitos que ellos autorizaron" ${ }^{20}$. Luego, refiriéndose explícitamente a la doctrina de las condiciones inconstitucionales, la Corte señaló que tal doctrina "se refiere a situaciones en las cuales el gobierno ha impuesto una condición en el receptor del subsidio más que en un programa o servicio particular, prohibiendo de ese modo, que el receptor realice la conducta prohibida fuera del ámbito del programa financiado con fondos federales" 21 .

Un análisis similar es el que la Corte hace en un caso más reciente. En United States v. American Library Association, la Corte declara la constitucionalidad de una ley que prohibía financiar con fondos federales las conexiones de internet en bibliotecas públicas que no tuvieran software que permitieran bloquear imágenes obscenas o pornografía infantil. En la opinión mayoritaria, el juez Rehnquist reconoció que el Congreso tenía límites más bien amplios al momento de asignar el gasto público: le ley en cuestión, escribió, "no 'penaliza' a las bibliotecas que eligieron no instalar el software, tampoco les niega el derecho a entregar sus servicios con un acceso a internet sin filtro alguno. Más bien, (la ley) simplemente refleja la decisión del Congreso de no subsidiar a quienes actúan de ese modo"22.

Tanto en Rust como en American Libraries Association, la Corte Suprema declaró la constitucionalidad de la asignación condicionada. Como lo destaca la doctrina, ambas sentencias se construyen sobre la base de la distinción entre una sanción y un subsidio. Dado que en ambos casos se estaría frente a un subsidio -argumenta la Corte- no puede sostenerse que el Congreso esté obligando a renunciar a un derecho. Si bien la distinción entre sanción y subsidio puede entenderse en la teoría, no es sencillo hacerla en la práctica. Esta dificultad se aprecia con claridad si analizamos otros dos casos en los que las condiciones fueron declaradas inconstitucionales.

\footnotetext{
18 Rust v. Sullivan (1991).

19 FARBER et al. (2003) y MASSEY (2005).

20 Rust v. Sullivan (1991) p. 196.

${ }^{21}$ Rust v. Sullivan (1991) pp. 196 y 197.

22 United States v. American Library Association (2003) p. 212.
} 
En FCC v. League of Woman Voters of Cal. ${ }^{23}$, la Corte Suprema declaró la inconstitucionalidad de una disposición que prohibía incorporar contenidos propios de la línea editorial a cualquier canal de televisión educativo que recibiera fondos públicos. La Corte señaló que la condición era inconstitucional porque inhibía todas las actividades editoriales de la estación televisiva. Por ejemplo, señala la Corte, un canal educativo en el que solo $1 \%$ de sus ingresos totales son fondos públicos tendría completamente prohibido editorializar. Luego agrega que "la estación no tiene opción de limitar el uso de fondos federales a todas las actividades donde no se editorializa, y, aún más importante, tiene prohibido incluso el uso de fondos totalmente privados para financiar sus tareas de editorialización" 24 . En consecuencia, la prohibición legal se declaró inconstitucional aun cuando ella solo se activaba cuando las estaciones de televisión aceptaban libremente recibir fondos federales.

El segundo caso es Legal Services Corp. v. Velázquez ${ }^{25}$. Legal Service Corporation distribuía fondos federales con miras a financiar la asistencia jurídica de los más pobres. En una de las tantas leyes de presupuesto de EE.UU., el gobierno central interpretó que el Congreso habría condicionado la entrega de recursos a dicha institución solo para aquellos casos en que los abogados participantes del programa de asistencia jurídica no alegaran la inconstitucionalidad de ciertas leyes sociales. La Corte Suprema declaró la inconstitucionalidad de la disposición porque esta "distorsiona el sistema legal al alterar el rol tradicional de los abogados" y porque "prohíbe la libertad de expresión de la cual depende el correcto ejercicio del poder judicial" 26 . Una vez más, el caso comprende un programa financiado con fondos federales al que nadie está obligado a acudir. Aun así, la Corte consideró inconstitucional la condición impuesta.

\section{ii. Derechos de Propiedad y Condiciones Inconstitucionales}

Las decisiones paradigmáticas de aplicación de la doctrina de las condiciones inconstitucionales en casos relacionados con derechos de propiedad se vinculan, más que con asignaciones de fondos públicos, con permisos que órganos gubernamentales conceden a propietarios. Como se verá, la doctrina ha servido para limitar las condiciones que pueden exigirse para permitir cambios en la propiedad de los individuos.

Nollan et ux. v. California Coastal Commission ${ }^{27}$ es el primer ejemplo. En este caso, la Corte Suprema rechazó la interpretación de la Corte de Apelaciones de California que había autorizado el condicionamiento de un permiso para construir la residencia de veraneo de la familia Nollan a la entrega por parte de estos de una franja de terreno de su propiedad. Esta última se ubicaba en la playa y la Comisión Costera de California argumentaba que la franja cedida mejoraría el acceso $^{28}$.

23 FCC v. League of Woman Voters of Cal. (1984).

${ }^{24}$ FCC v. League of Woman Voters of Cal. (1984) p. 400.

${ }^{25}$ Legal Services Corp. v. Velázquez (2001).

${ }^{26}$ Legal Services Corp. v. Velázquez (2001) p. 545.

27 Nollan et ux. v. California Coastal Commission (1984).

28 Una mirada a Nollan desde la perspectiva de las regulaciones expropiatorias en DeLAVEAU (2006). 
El juez Scalia, quien escribe el voto de mayoría, señaló que la entrega sin compensación de una franja de propiedad viola claramente la enmienda XIV ${ }^{29}$. Sin embargo, en este caso la pregunta en la que se centra es "si el requisito de entregar la propiedad como una condición para autorizar un determinado uso del terreno altera el resultado" ${ }^{30}$. La Corte responde lo que sigue:

"Si la Comisión hubiera impuesto a un determinado permiso la condición de proteger la posibilidad de la gente de ver la playa (...) -por ejemplo, una limitación a la altura, una restricción en el porte o una prohibición a rejas o murosdado que la Comisión podría haber ejercido sus facultades (como asumimos que hubiera podido) para prohibir la construcción de toda la casa, la condición mencionada seria también constitucional. Es más (y aquí nos acercamos al presente caso), la condición sería constitucional incluso si esta hubiera exigido a los Nollans un espacio en su propiedad para que quienes pasen por fuera puedan ver el mar (...). La facultad de la Comisión de prohibir la construcción de su casa en orden a proteger la vista de la playa incluye seguramente la facultad de condicionar la construcción a alguna concesión del dueño, incluso a alguna concesión de derechos de propiedad que sirven el mismo objetivo (...) La evidencia constitucional desaparece, sin embargo, si la condición o la prohibición fracasa completamente en alcanzar el objetivo que justificaba a la prohibición" ${ }^{31}$.

Finalmente, aplicando estos principios al caso particular, la Corte concluyó que "la falta de nexo entre la condición y el propósito original de la restricción transforma el propósito en algo distinto de lo que es. El propósito entonces se transforma, simplemente, en la obtención de una franja de terreno para alcanzar un válido propósito del gobierno pero sin el pago de la compensación debida"32.

En otras palabras, para este caso particular, la condición -ceder una franja de propiedad- fue declarada inconstitucional porque ella no tenía un nexo esencial con el propósito que había servido de fundamento para prohibir la construcción -que esta interfería la vista que los paseantes pudieran tener de la playa-.

Años después, la Corte tuvo la oportunidad de revisar el estándar del nexo esencial que había creado en Nollan. En Dolan v. City of Tigard ${ }^{33}$ la Corte Suprema declaró inconstitucional una regulación de la Comisión Planificadora de la Ciudad que requería como condición para autorizar la expansión de la tienda de la Sra. Dolan, la dedicación de un espacio de su terreno a áreas verdes públicas y a una ciclovía.

\footnotetext{
29 En lo que importa, la Enmienda XIV establece que "tampoco podrá Estado alguno privar a cualquier persona de la vida, la libertad o la propiedad sin el debido proceso legal”. (Traducción del Departamento de Estado de los Estados Unidos).

30 Nollan et ux. v. California Coastal Commission (1984) p. 834.

${ }^{31}$ Nollan et ux. v. California Coastal Commission (1984) p. 836.

32 Nollan et ux. v. California Coastal Commission (1984) p. 837.

${ }^{33}$ Dolan v. City of Tigard (1994).
} 
En Dolan la Corte analizó como primer paso -siguiendo Nollan- la existencia de un nexo esencial entre 'el interés legítimo del Estado' y la condición que imponía la Comisión. En este punto consideró que lo había, pues "existe un nexo entre prevenir los aluviones a lo largo del estero Fanno y limitar el desarrollo urbano dentro de planicie aluvial que rodea al estero". En el mismo sentido, añadió que la Corte reconoce que "en teoría, una ciclovía entrega una alternativa de transporte para los trabajadores y los compradores" 34 .

Sin embargo, el caso no logró superar el análisis de proporcionalidad que exigió la Corte como segundo requisito. Como el juez Rehnquist destacó en una de sus últimas frases en el caso, "las metas de la ciudad, como reducir el riesgo de aluviones y la congestión vehicular, y aumentar las áreas verdes públicas, son valiosas, pero hay límites externos al modo como pueden alcanzarse" 35 .

En los años siguientes, diversas cortes han aplicado los criterios sentados en Nollan y Dolan. De hecho, como acredita la investigación de David Callies, tanto los tribunales estatales como los federales "parecieran haber adoptado completamente tanto el nexo esencial como el requisito de proporcionalidad" 36 .

En consecuencia, las condiciones fueron declaradas inconstitucionales a pesar que, en ambos casos, la Corte reconoce que la autoridad urbana tiene el derecho a negar del todo las peticiones de los propietarios. Una vez más, surge la pregunta: ¿por qué sería inconstitucional autorizar bajo condición algo que la instancia gubernamental no estaría obligada a autorizar?

\subsection{CONDICIONES PERMisibles E IMPERMisibles: EL ANÁlisis DE LOS ACADÉMICOS}

La discusión académica en torno a la doctrina de las condiciones inconstitucionales es antigua. Ya se han mencionado los primeros trabajos que enunciaron su existencia. En las próximas páginas analizaremos brevemente algunas publicaciones de académicos en torno al tema. En general todos ellos resaltan la importancia de una doctrina sólida y consistente a la vez que plantean algunos criterios o aproximaciones que, de ser aplicadas, permitirían señalar cuándo una asignación condicionada es inconstitucional. Luego se destacarán las dudas que la existencia de la doctrina genera en otro grupo de académicos demostrando, de esta forma, que el tema está lejos de quedar zanjado aún en el país que lo vio nacer.

i. Seth Kreimer. El primer trabajo de los que analizaremos fue publicado a mediados de los ochenta por el hoy profesor de la Facultad de Derecho de la Universidad de Pennsylvania, Seth Kreimer. En su investigación sobre el tema, más de una vez advierte de los "peligros que para la libertad plantea el Estado moderno, los que residen tanto en lo que este deja de hacer como en lo que efectivamente hace" 37 .

${ }^{34}$ Dolan v. City of Tigard (1994) p. 387.

35 Dolan v. City of Tigard (1994) p. 396.

36 Callies (1999) p. 567.

37 Kreimer (1984) p. 1396. 
Con miras a proponer un mecanismo para dilucidar si una condición específica es o no permisible, Kreimer distingue entre amenazas y ofertas. Las primeras son "asignaciones que dejan a los ciudadanos en una situación peor a la que, de otro modo, estarían enfrentados al ejercer un derecho constitucional". Las segundas, es decir las ofertas, "simplemente expanden el rango de opciones, dejando al ciudadano en una mejor situación" 38 . Mientras las amenazas merecen un riguroso escrutinio constitucional, las ofertas están libres de todo límite.

Para hacer la distinción, Kreimer sugiere tres criterios que deben estar presentes en el análisis: 1) Historia, es decir, si el beneficio ha sido entregado en el pasado; 2) Igualdad de trato; y 3) Predicción o, en otras palabras, qué hubiera hecho el gobierno si no hubiera podido imponer tal condición. Junto a este análisis, Kreimer propone que, aun cuando la asignación no reduzca libertades individuales, esta sería inconstitucional si el derecho en cuestión es inalienable.

Finalmente, asumiendo lo complejo del tema, el autor reconoce que no es su intención que el análisis de los tres factores propuestos provea una solución a los casos mas difíciles, sino que simplemente facilite la consideración del asunto.

ii. Kathleen Sullivan. En un sentido similar se pronuncia una de las más importantes investigaciones en el tema ${ }^{39}$. La ex decana de la Facultad de Derecho de la Universidad de Stanford, Kathleen Sullivan escribe que "la doctrina de las condiciones inconstitucionales responde al temor constante que el gobierno tienda a usar la manipulación estratégica de beneficios gratuitos para aumentar el poder del Estado" ${ }^{40}$. Una de sus principales preocupaciones es que "las inequidades de origen tanto en dinero como en recursos necesariamente determinan la posición negociadora de cada cual en relación al gobierno, y (...) que los pobres pueden no tener nada que negociar salvo sus propias libertades" ${ }^{41}$.

Por esta razón, a diferencia de Kreimer, Sullivan propone que la pregunta se centre "no en el individuo beneficiado, en el proceso legislativo o en la posibilidad de renunciar al derecho, sino que en el efecto sistemático de las condiciones en la distribución de los derechos en la sociedad como un todo" ${ }^{42}$. Desde esta perspectiva, las cortes debieran aplicar el máximo de escrutinio cada vez que el gobierno crea una condición cuyo fin o efecto principal "es presionar al receptor con miras a alterar su elección en el ejercicio de una libertad constitucional en una dirección favorecida por el gobierno” 43 .

iii. Richard Epstein. Este es otro de los académicos que ha dedicado parte de sus investigaciones al tema ${ }^{44}$. Epstein empieza sugiriendo el que para él constituye el proble-

\footnotetext{
38 Kreimer (1984) p. 1300.

39 SULLIVAN (1989).

40 Sullivan (1989) p. 1493.

41 SULLIVAN (1989) p. 1497.

42 Sullivan (1989) p. 1421.

43 SULLIVAN (1989) p. 1499.

${ }^{44}$ Entre otros, EPSTEIN (1993).
} 
ma de fondo: cómo "unir un sistema de gobierno discrecional (...) con un sistema de protección de los derechos individuales" 45 . Su mayor preocupación es construir un modelo efectivo de control del poder monopólico del Estado cuando negocia con los ciudadanos. En este modelo, esencial para la protección de los derechos individuales, la doctrina de las condiciones inconstitucionales representaría una importante limitación a la discreción pública.

Más que destacar criterios, Epstein simplemente recomienda un estricto escrutinio constitucional cuando el gobierno entra en negociaciones o pactos con las personas ${ }^{46}$. Para ello la doctrina de las condiciones inconstitucionales constituye una importante herramienta para estrechar la amplitud con que el Estado puede negociar con los individuos debido a que este tendrá que decidir, en definitiva, entre ofrecer el beneficio sin condición alguna o simplemente no ofrecerlo. Asumiendo esta dicotomía, la aplicación rigurosa de la doctrina incentivará la selección de la alternativa que asegure el mayor bienestar social.

iv. Brooks Fudenberg. En una investigación publicada en la Revista de la Facultad de Derecho de la Universidad de California, Los Angeles, Fudenberg da una completa mirada a la doctrina de las condiciones inconstitucionales desde sus inicios ${ }^{47}$. En este documento advierte, en la línea de Epstein, que lo relevante no es crear una teoría o una doctrina pues será imposible que esta resuelva todos los casos. Lo importante, nos dice, es profundizar en el grado de escrutinio que deben utilizar las cortes para declarar la constitucionalidad o inconstitucionalidad de este tipo de condiciones.

Para dilucidar lo anterior, Fudenberg profundiza en un tema directamente vinculado con la doctrina de las condiciones inconstitucionales. Este puede resumirse en el aforismo "quien puede lo más, puede lo menos" (doctrine of the greater and the lesser), es decir, si el gobierno puede negar todo el beneficio, también puede hacerlo en parte. Tras un extenso análisis de cómo se vinculan ambas doctrinas, el autor propone analizar la constitucionalidad de "lo menos" separadamente. Así, concluye, "si el gobierno busca separar en temas constitucionalmente sospechosos, debe aplicarse un escrutinio elevado. Si el gobierno busca separar en temas que no son constitucionalmente sospechosos, solamente se necesita un análisis de razonabilidad" 48 .

Para ejemplificar su criterio el autor señala que si un gobierno quiere entregar un beneficio exclusivamente a quienes ganen menos de US\$30.000 al año, el test que deben aplicar los jueces es el de razonabilidad pues la condición no se funda en un tema constitucionalmente sospechoso. En cambio si un empleador, que tiene el derecho a despedir a sus trabajadores, empieza a despedir solo a los de cierta raza, el tribunal debe aplicar un estándar más alto para decidir (compelling interest).

\footnotetext{
45 EPSTEIN (1989) p. 203.

46 EPSTEIN (1988) p. 103.

47 FUDENBERG (1995-1996).

48 Fudenberg (1995-1996) p. 463.
} 


\subsection{DUDAS}

La discusión en torno a la doctrina de las condiciones inconstitucionales, como se ha visto, se ha desarrollado desde hace años de la mano de las cortes y los académicos. Con todo, no es posible decir que se ha llegado a un consenso en el contenido, ámbito y perspectivas de la misma. Como se mencionó, desde los inicios de su enunciación, el juez Holmes la consideró inadecuada. Y es que, como confiesa Robert Hale en una de las primeras investigaciones publicadas al respecto, las críticas a la doctrina son comprensibles pues esta es difícil de sostener lógicamente. "Si no tengo opción de reclamar por habérseme negado de todo el privilegio -escribe Hale- es difícil ver cómo adquiero tal opción simplemente porque el Estado, en vez de negarme el privilegio, me ofrece una alternativa, por más dura que esta sea" ${ }^{49}$.

En la actualidad, mientras una serie de académicos resaltan la importancia de la doctrina, otros de igual peso afirman que esta no existe. Entre los últimos encontramos a Cass Sunstein como su exponente más importante. Una de sus publicaciones se titula "¿Existe una doctrina de las condiciones inconstitucionales?50. Su respuesta es negativa. Entre otros argumentos, Sunstein sostiene que la discusión es inadecuada pues esta, entre otras cosas, busca encontrar la distinción entre una pena y un subsidio. Este análisis, a juicio de Sunstein, no cae dentro del ámbito de acción de los Tribunales y, por ello, en casi todas las oportunidades las cortes no pueden resolverlo. En la misma línea, en otro de sus textos agrega que cualquier criterio que se cree en torno al tema de las condiciones inconstitucionales llevará a los jueces a ignorar la extraordinaria particularidad de los problemas que se construyen en torno a la doctrina ${ }^{51}$.

Por su parte, Frederick Schauer califica la problemática que plantea la doctrina de las condiciones inconstitucionales dentro de aquellas que la teoría constitucional no puede solucionar. Ello, según argumenta, pues "estamos buscando principios coherentes y doctrinas utilizables en áreas políticas donde predominan las cuestiones de grado y donde límites arbitrarios son temporalmente necesarios pero no para resolver en un sentido más profundo complejos objetivos políticos en competencia" 52 .

En la misma línea, un miembro de la Corte Suprema de Estados Unidos ha reconocido en uno de sus votos de minoría que "la doctrina de las condiciones inconstitucionales ha sufrido, durante mucho tiempo, de una aplicación notoriamente inconsistente; ella nunca ha sido, agrega, un principio constitucional amplio que opera con igual fuerza en toda situación, sin importar la naturaleza del derecho y los poderes en juego" 53 .

Así las cosas, si bien la doctrina tiene fundamento en el derecho de Estados Unidos, lo cierto es que sus límites reales e implicancias son y seguirán siendo objeto de profunda discusión tanto en las universidades como en los tribunales. Esta primera aproximación, sin embargo, nos permite vislumbrar el estado del debate y comprender

\footnotetext{
${ }^{49}$ Hale (1935) p. 322.

50 SUNSTEIN (1989).

51 SUNSTEIN (1989) p. 345. Ver también SUNSTEIN (1990).

52 SCHAUER (1994-1995) p. 990.

53 Dolan v. City of Tigard (1994) (Voto de minoria de Stevens).
} 
los fundamentos sobre los que se construye dicha doctrina. De este modo, se abre la opción de aplicar dichos fundamentos y encontrar casos similares a los descritos para intentar aplicar en nuestro derecho la doctrina de las condiciones inconstitucionales.

Para ello, en las páginas que siguen, se estudiarán algunas leyes y prácticas jurídicas nacionales que permitirán vislumbrar la aplicación de la doctrina de las condiciones inconstitucionales en el derecho nacional.

\section{ALGUNOS CASOS DE APLICACIÓN EN CHILE: PRIMERAS APROXIMACIONES A LA DOCTRINA DE LAS CONDICIONES INCONSTITUCIONALES}

¿Podría tener aplicación esta doctrina en Chile? Como veremos, creemos que no solo existe el espacio para su concreción sino que también la necesidad de que eso ocurra para así levantar una nueva protección a los derechos de las personas que negocian con el Estado. Si bien el Tribunal Constitucional nunca ha hecho referencia a ella, ha habido casos en que la doctrina de las condiciones inconstitucionales podría haber iluminado y complementado la decisión final. Por esta razón se destacan a continuación algunos fallos del Tribunal Constitucional que pueden ir dando forma a una futura aplicación de estos principios en la jurisprudencia nacional.

Con todo, y antes de volver la vista hacia nuestro país, no está de más una breve referencia a una discusión académica que se vincula tangencialmente con esta investigación. Diversos profesores de derecho comparado han debatido en torno a si es o no posible trasplantar o importar sistemas legales. Ejemplifican adecuadamente estas dos visiones la polémica sostenida por los profesores Alan Watson y Pierre Legrand. Watson sostiene que la importación desde otros sistemas jurídicos es la forma más común de cambio legal. Es lo que él denomina el "el trasplante legal": Europa recibió el Derecho Romano, Latinoamérica recibió el derecho español y el francés, y el imperio inglés esparció la ley inglesa por todos sus territorios. Por su parte, Legrand rechaza cualquier posibilidad de trasplante legal pues señala que la ley está tan enraizada en la tradición que simplemente no es posible traer legislación extranjera y aplicarla. "En el mejor de los casos, agrega, solo puede ser llevado de un sistema a otro un conjunto de palabras sin sentido. Pedir más, es pedir demasiado" 54 . No es del caso entrar a analizar en esta investigación ambas visiones aun cuando conviene considerarlas a fin de evitar que se importe ciegamente los fundamentos y conclusiones de doctrinas extranjeras. No es eso lo que se propone en estas páginas. Más bien, el objetivo es proponer una mirada comparada a una disyuntiva constitucional debatida en el extranjero que también se ha presentado en nuestro país. Empezar a considerar esta perspectiva en el estudio del

54 Legrand (1997) p. 120. Una réplica en WATSON (2000). Para una discusión similar ver también BERKOWITZ et al. (2003) (señalando que los países que han desarrollado sus propias normas en un sistema de prueba y error tienen una institucionalidad más efectiva que aquellos donde el derecho extranjero ha sido impuesto externa más que interna) y ROSENKRANTZ (2003) (que analiza diversos argumentos a favor y en contra del trasplante en el derecho constitucional). 
derecho constitucional no hace sino ofrecer una nueva aproximación a contiendas jurídicas enriqueciendo el debate y el análisis. En ese espíritu se insertan las páginas que siguen.

\subsection{ARTÍ́CUlO $19 \mathrm{~N}^{\circ} 26$}

El artículo 19 No 26 de la Constitución podría constituirse en un primer e importante sustento de la doctrina de las condiciones inconstitucionales en el texto de la Carta Fundamental. En lo pertinente, la disposición establece que la Constitución asegura a todas las personas "la seguridad de que los preceptos legales que por mandato de la Constitución regulen o complementen las garantías que esta establece o que las limiten en los casos que ella lo autoriza, no podrán afectar los derechos en su esencia, ni imponer condiciones, tributos o requisitos que impidan su libre ejercicio".

Esta norma es de enorme importancia al punto que ha llevado a Bertelsen a señalar que sus fundamentos, es decir, la protección de la esencia de los derechos humanos, es "una de las grandes innovaciones del constitucionalismo posterior a la II Guerra Mundial" 55 . En la misma línea Evans la ha calificado como "la más importante garantía constitucional, la más novedosa y esperamos que la más eficaz" 56 .

Como se dijo, este numeral puede servir como fundamento de texto de la doctrina que analizamos. En efecto, la norma prohíbe explícitamente la imposición de condiciones que impidan el libre ejercicio de las garantías constitucionales. Sin embargo, aun se requiere profundizar en su aplicación para entrever criterios y situaciones en los que las condiciones serían impermisibles y aquellos en los cuales estas no tendrían reparos constitucionales. Ello puesto que, como ha dicho el Tribunal Constitucional, el puro hecho que se establezcan requisitos "para el ejercicio de un derecho consagrado por la Constitución Política, no constituye necesariamente y por sí mismo una causal de inconstitucionalidad de la norma que así lo haga. Tampoco necesariamente siempre tales requisitos constituirán un impedimento para el ejercicio de ese derecho" 57 . En consecuencia corresponde preguntarse cuándo nos enfrentamos a condiciones que impiden el libre ejercicio de un derecho y cuándo dichas condiciones son solo requisitos admisibles que, aún limitando el ejercicio de una garantía, no lo impiden.

La jurisprudencia de la Corte Constitucional nos entrega algunos indicios para responder esta pregunta. Muy tempranamente definió que "un derecho es afectado en su 'esencia' cuando se le priva de aquello que le es consubstancial de manera tal que deja de ser reconocible y que se 'impide el libre ejercicio' en aquellos casos en que el legislador la somete a exigencias que lo hacen irrealizable, lo entraban más allá de lo razonable o lo privan de tutela jurídica" 58 .

\footnotetext{
55 Informe en Derecho citado en Sentencia del Tribunal Constitucional Rol No 280 (1998) c. 22.

56 EVANS (1999) p. 293.

57 Sentencia del Tribunal Constitucional Rol No 200 (1994)c. 3. Declarando inconstitucional un requisito que un proyecto de ley exigía para poder constituir una junta de vecinos pues impedía el libre ejercicio del derecho de asociación.

58 Sentencia del Tribunal Constitucional Rol No 43 (1987) c. 21 . Señalando que no afecta la esencia del derecho de asociación ciertos requisitos que la ley impone para la formación de partidos políticos.
} 
Años más tarde, en el fallo "Ley de Prensa" el tribunal propone un test para analizar las limitaciones o restricciones a los derechos fundamentales. Se establece que "tales limitaciones deben ser señaladas con absoluta precisión, a fin de que no sea factible una incorrecta o contradictoria interpretación. Asimismo, esa exigida precisión debe permitir la aplicación de las restricciones impuestas de una manera igual para todos los afectados, con parámetros incuestionables y con una indubitable determinación del momento en que aquellas limitaciones nacen o cesan"59. Una sentencia posterior viene a complementar este criterio cuando dice que las limitaciones que se analizan "deben estar establecidas con parámetros incuestionables, esto es, razonables y justificados" para luego agregar que "el derecho se dificulta más allá de lo razonable cuando las limitaciones se convierten en intolerables para su titular". Finalmente el mismo fallo incorpora dos nuevos elementos de difícil precisión que deben tenerse en consideración: en primer lugar, nos dice, "el momento histórico de cada situación concreta, por el carácter evolutivo del contenido esencial del derecho; y luego, las condiciones inherentes de las sociedades democráticas, lo que alude a determinar el sistema de límites del ordenamiento jurídico general y cómo juega en ella el derecho y la limitación" 60 .

Estas sentencias entregan un marco de interesantes perspectivas para la aplicación de la doctrina en Chile pues analizan cuándo la limitación a un derecho fundamental sería inadmisible. Podría argumentarse, con todo, que la doctrina de las condiciones inconstitucionales se aplica en supuestos distintos a los que motivaron estos fallos. En efecto, tradicionalmente, el artículo 19 No 26 se invoca frente a preceptos que regulan o limitan las garantías constitucionales y no, como propone la doctrina de las condiciones inconstitucionales, cuando el Estado impide o limita en su esencia el ejercicio de una garantía constitucional -porque exige renunciar a ella- pero en circunstancias distintas a las tradicionales, esto es, cuando distribuye un subsidio o da un permiso que no está obligado a entregar. ¿Se puede aplicar en este caso el mismo test? Consideramos que sí pues el texto constitucional no hace ningún distingo y, en consecuencia, la protección de los derechos fundamentales con la que se compromete la Carta Fundamental es una protección universal. No es consistente argumentar que el marco constitucional protege los derechos fundamentales en ciertas circunstancias y no en otras donde esos mismos derechos están en riesgo. Por ello cuando las condiciones que imponga el Estado para recibir un subsidio o para dar un permiso que no está obligado a entregar importan imponer sobre el titular del derecho cargas no razonables, injustificadas o intolerables

\footnotetext{
59 Sentencia del Tribunal Constitucional Rol No 226 (1995) c. 47. Declarando inconstitucional un artículo de la ley de prensa establecer ciertas limitaciones al ejercicio de derechos fundamentales sin que hubieran concurrido los elementos esenciales para establecer una restricción.

60 Sentencia del Tribunal Constitucional Rol No 280 (1998) c. 29 (no son inconstitucionales ciertos aumentos al impuesto al tabaco y a los combustibles). Estos criterios han sido reiterados en otros fallos más recientes tales como Rol No 513 (2007) c. 20 (en el que se analiza el contenido del derecho a desarrollar cualquier actividad económica); Rol No 541 (2006) c. 14 (en relación a la proporcionalidad del pago de una compensación cuarenta veces superior al monto adeudado en caso de no pago de peaje en carreteras concesionadas); Rol No 546 (2006) c. 12 (analizando la obligación de consignar un porcentaje de la multa para acceder a un órgano jurisdiccional); Rol No 792 (2008) c. 13 (analizando ciertas limitaciones impuestas en el Código Sanitario para acceder a la justicia).
} 
-utilizando las expresiones usadas por el TC- el artículo 19 No 26 es el llamado a acoger la doctrina de las condiciones inconstitucionales.

Finalmente, cabe señalar que la academia también ha tratado estas materias aun cuando el foco suele estar dirigido a analizar aquello que compondría el núcleo esencial de las diversas garantías ${ }^{61}$. Sin embargo, debe destacarse que, en lo que respecta al condicionamiento en el ejercicio de las garantías constitucionales, se ha escrito que el numeral 26 busca garantizar "el sentido de proporcionalidad entre el medio utilizado para limitar o restringir el derecho y la finalidad de bien común que con esa limitación o restricción se pretende alcanzar" 62 . De este modo, Varas y Mohor incorporan a este análisis un test de proporcionalidad de interesantes perspectivas para una futura aplicación de la doctrina de las condiciones inconstitucionales en nuestro derecho. En efecto, como hemos visto, un test similar fue incorporado por la Corte Suprema de Estados Unidos al momento de vincular la doctrina en estudio con los derechos de propiedad.

\subsection{EDUCACIÓN}

En esta materia la doctrina de las condiciones inconstitucionales se vincula con la subvención educacional que el Estado entrega a ciertos establecimientos, tanto privados como públicos, por concepto de asistencia diaria a clases de sus estudiantes ${ }^{63}$.

\section{i. Subvención Educacional}

El texto legal que fija los requisitos para impetrar la subvención es el Decreto con Fuerza de Ley No 2, de 1996, del Ministerio de Educación. Específicamente en su artículo $6^{\circ}$ se enumeran una serie de exigencias que debe cumplir el establecimiento que aspire a recibir la subvención. Entre otras, deben estar reconocidos oficialmente, sus alumnos por curso deben ajustarse al mínimo y máximo permitido por el Ministerio, no deben exigir aportes económicos ni cobros como exigencia de ingreso o permanencia al establecimiento, etc.

Con motivo de la discusión y aprobación de la ley 19.979, se incorporó al artículo otra serie de condiciones que debían concurrir para impetrar la subvención ${ }^{64}$. La más discutida fue aquella que exigía que al menos un 15\% de los alumnos de los establecimientos presenten condiciones de vulnerabilidad económica. De hecho, esta y otras modificaciones fueron impugnadas ante el Tribunal Constitucional.

El fallo de dicha instancia presenta un interesante análisis de la libertad de enseñanza y el derecho a la educación. Adicionalmente es posible apreciar en algunos de sus

\footnotetext{
${ }^{61}$ Entre otros ARÓstica (2001) p. 83 y ss.; CEA (2004) p. 591 y ss.; Fermandois (2001) p. 294-296; FERNÁNDEZ (2006) p. 128-135. Ver también SEGPRES (2000).

62 VARAS y MOHOR (1997) p. 165.

63 En Chile existen establecimientos educacionales particulares pagados, particulares subvencionados y municipales. Los dos últimos reciben una subvención que aporta el Estado por concepto de asistencia diaria de los estudiantes. Es este un subsidio a la demanda. Dentro de los establecimientos particulares subvencionados existen también algunos con financiamiento compartido, esto es, aquellos en que los padres aportan una cuota de dinero mensual reduciéndose con ello la subvención estatal. Para una visión general de este tema ver VIVANCO (2007).

${ }^{64}$ Ley No 19.979 , de 2004.
} 
fundamentos un análisis similar al que sirve de base en Estados Unidos para la aplicación doctrina de las condiciones inconstitucionales. Señaló el Tribunal en dicha ocasión que:

"Para recibir la subvención educacional dichos establecimientos (los privados) se hallan obligados a cumplir determinadas exigencias legales, las cuales, hasta hoy, son adecuadas y proporcionadas al control que ella lleva consigo y, por lo mismo, resultan ponderadas y razonables en relación con la finalidad lícita referida. En esta medida, por ende, la intervención estatal (...) se concilia con la libertad y autonomía explicadas, resultando así inobjetable desde el ángulo constitucional" ${ }^{65}$.

Como puede apreciarse, los requisitos que la ley puede exigir a los receptores de la subvención podrían, en el futuro, ser inadecuados, desproporcionados o irrazonables para alcanzar su fin. Si bien no se habla de condicionamiento inconstitucional, sí podría señalarse que hay una limitación a la capacidad que tiene el Estado de condicionar la entrega de recursos públicos.

Con todo, hay un importante aspecto que aleja nuestro ejemplo de la doctrina de Estados Unidos. Interpretando el inciso quinto del artículo 19 No 10 de la Constitución ${ }^{66}$, el propio Tribunal expresa que "otorgar la subvención no es una decisión de cumplimiento discrecional ni entregada a la magnanimidad del Estado. Por el contrario, trátase de una obligación ineludible, cuya justificación radica en la importancia excepcional que tienen la educación y la enseñanza en el desarrollo libre de la personalidad y de la sociedad en general" 67 .

En consecuencia, podría argumentarse que la obligación de entregar la subvención a la que está sujeto el Estado impide que este imponga requisitos desproporcionados pues esto llevaría a un incumplimiento de su obligación. En otras palabras, el Estado no tiene entera libertad para imponer condiciones cuando la Constitución lo obliga a entregar el beneficio.

\section{ii. Subvención Preferencial}

El elemento de obligatoriedad distingue este caso de los otros que hemos analizado a propósito de la aplicación de la doctrina de las condiciones inconstitucionales en Estados Unidos. Sin embargo, esta distinción desaparece en el caso de la Ley No 20.248 que establece una subvención escolar preferencial ${ }^{68}$. En esta ley se aumenta la subvención de ciertos alumnos cuando estos son calificados como alumno prioritario. Lo interesante es que el Estado condiciona la recepción de la subvención a una serie de requisitos que se imponen al establecimiento educacional.

65 Sentencia del Tribunal Constitucional Rol No 410 (2004) c. 26. Un análisis de este fallo se puede ver en BERTELSEN (2005) p. 157-195 y también en SOTO (2005) p. 259-281.

66 "Corresponderá al Estado, asimismo, fomentar el desarrollo de la educación en todos sus niveles; estimular la investigación científica y tecnológica, la creación artística y la protección e incremento del patrimonio cultural de la Nación".

${ }^{67}$ Sentencia del Tribunal Constitucional Rol No 410 (2004) c. 19.

${ }^{68}$ Ley No 20.248, de 2008. 
Uno de los requisitos que generó mayor resistencia exigía que la escuela no seleccionara alumnos de acuerdo a su proyecto educativo sino que debía, en última instancia y si los postulantes superaban a los cupos ofrecidos, realizar un sorteo para determinar quiénes ingresarían al establecimiento. Esta norma fue modificada en las últimas etapas del proyecto de ley tras el acuerdo educacional que alcanzaron el Gobierno, la Concertación y la Alianza ${ }^{69}$. En su reemplazo el texto definitivamente aprobado -que limita en mucho menor grado la libertad de enseñanza- está contenido en el artículo $6^{\circ}$ letra b) que impone como condición para impetrar la subvención preferencial que los establecimientos acepten "a los alumnos que postulen entre el primer nivel de transición y sexto básico, de acuerdo a procesos de admisión que en ningún caso podrán considerar el rendimiento escolar pasado o potencial del postulante".

La ley también hace otra serie de exigencias a los establecimientos que quieran acceder a la subvención preferencial. Entre otras, estos no podrán expulsar alumnos por razones académicas entre el primer nivel de transición y sexto año básico ${ }^{70}$. También deberán celebrar un convenio con el Ministerio de Educación que, en términos generales, interviene en una serie de materias que tradicionalmente se entienden dentro de la esfera de competencias del establecimiento (la exigencia de actividades artísticas, culturales y deportivas en la malla curricular; existencia de diversas instancias de participación; etc. $)^{71}$. Finalmente, en la misma línea, la normativa exige la existencia de un Plan de Mejoramiento Educativo que interviene en la organización del establecimiento y en la gestión del currículo, de los docentes y de los recursos ${ }^{72}$.

Todo esto, podría argumentarse, implica renunciar a un derecho fundamental cual es la libertad de enseñanza de los establecimientos. En otras palabras, se estaría condicionando la recepción de un beneficio -la subvención preferencial- a la renuncia de un derecho fundamental, cual es, la libertad de enseñanza. Un componente esencial de dicha libertad es el derecho a organizar el establecimiento educacional que, como ha dicho el Tribunal Constitucional, que comprende "determinar, los fundadores o quienes les sigan, las características del establecimiento en nexo con sus finalidades u objetivos y métodos para lograrlos; rasgos típicos de la docencia y de los profesionales que la lleven a cabo; régimen de dirección, administración y responsabilidad; reglas pertinentes al orden y disciplina en la convivencia interna; sistema financiero o vínculos con otras instituciones (...) En síntesis, en este primer aspecto, la libertad de enseñanza supone el respeto y protección de la plena autonomía, garantizada por la Constitución en favor del fundador o sostenedor del establecimiento respectivo, para la consecución de su proyecto educativo, en los ámbitos docente, administrativo y económico"73.

En síntesis, como en los casos analizados de la jurisprudencia de Estados Unidos, el Estado no tiene ninguna obligación de entregar esta subvención pero, la cuestión

\footnotetext{
${ }^{69}$ Ver Primer Informe Complementario de Educación, Cultura, Ciencia y Tecnología. (2007) Boletín 4030-04.

70 Artículo 6o, letra d).

${ }^{71}$ Artículo 7o.

72 Artículo $8^{\circ}$.

73 Sentencia del Tribunal Constitucional Rol No 410 (2004) c. 10.
} 
sería, si una vez que decide hacerlo tiene alguna restricción. La doctrina de las condiciones inconstitucionales respondería afirmativamente.

Por último cabe destacar la prevención de los ministros Bertelsen, Vodanovic y Correa. Como el proyecto contenía algunas normas de rango orgánico constitucional, fue analizado por el Tribunal Constitucional al que le correspondió pronunciarse de la norma que imponía una de las condiciones mencionadas: la limitación a los procesos de selección. En la sentencia el voto de mayoría solo califica la norma como acorde a la Constitución sin mayor desarrollo. En cambio, la prevención se detiene y realiza un análisis más profundo. Señalan los ministros que la norma en cuestión "limita la libertad de los sostenedores de establecimientos educacionales que tengan interés en impetrar las subvenciones establecidas en el proyecto de ley en examen en lo que respecta a la selección de los alumnos que postulan a ingresar al establecimiento que sostienen”. No obstante ello, nos dicen, "tales limitaciones, consistentes en no poder considerar el rendimiento escolar pasado o potencial del estudiante o los antecedentes socioeconómicos de la familia, tienen directa relación con el legítimo propósito de la ley de integrar mejor en el proceso educativo a los alumnos de familias vulnerables y retenerlos en el mismo, que es lo que justifica la subvención educacional preferencial que se crea, razón por la que no constituyen una vulneración de la libertad de enseñanza"74.

La prevención es sumamente interesante para efectos de esta investigación. Ello por cuanto implícitamente reconoce la existencia de las bases de una doctrina de las condiciones inconstitucionales. En efecto, la prevención analiza si hay violación de la libertad de enseñanza aun cuando quien accede al beneficio de la subvención preferencial no está obligado a hacerlo ni el Estado a entregarlo. Sin embargo, reflexiona el texto de la prevención, ello no es obstáculo para prevenir que si hubiera un atentado efectivo a los derechos fundamentales -en este caso, la libertad de enseñanza- la norma no sería admisible.

En definitiva, es este un pequeño paso concreto y positivo hacia una concreción real de la doctrina de las condiciones inconstitucionales en nuestro derecho. El Tribunal Constitucional, con la sentencia de 2004 complementada con la prevención de 2008, se aproxima a ella. Solo falta explicitarla y analizar las contiendas desde esta nueva perspectiva.

\subsection{EXENCIONES DEL IMPUESTO TERRITORIAL}

A fines de noviembre de 2007 el Tribunal Constitucional dictó tres sentencias que se vinculan con la materia a propósito de recursos de inaplicabilidad por inconstitucionalidad de una disposición de la ley de Rentas Municipales. Los recurrentes fueron la Sociedad Palestina S.A., Sociedad Anónima de Deportes Manquehue y Estadio Español S.A., todos con los mismos fundamentos ${ }^{75}$.

Los actores reclamaron, en lo que interesa para esta investigación, que la condición impuesta a los recintos deportivos de carácter particular para que pudieran acceder

\footnotetext{
${ }^{74}$ Sentencia del Tribunal Constitucional Rol No 1022 (2008) p. 10.

75 Sentencias del Tribunal Constitucional Roles No 718, 759 y 773 (2007). Un análisis de estos fallos puede verse en AVILÉS (2008) p. 165-180.
} 
a la exención del impuesto territorial era inconstitucional. El Tribunal desafortunadamente no entró a conocer del asunto ni entregó pistas utilizables para el futuro.

Veamos el asunto en detalle. El artículo $2^{\circ}$ de la ley $20.033^{76}$ modificó la Ley 17.235 sobre Impuesto Territorial. Esa disposición consolidó en un solo cuadro, contenido en el anexo de la ley, todas las exenciones al impuesto territorial existentes que, hasta antes de la publicación de la ley, se encontraban diseminadas en diversos cuerpos legales.

Los clubes deportivos, que hasta la fecha estaban exentos del impuesto territorial, vieron cómo durante la tramitación legislativa el marco regulatorio que los regía sufrió modificaciones. En efecto, un grupo de diputados y luego el Ejecutivo en la Comisión Mixta presentaron una indicación para condicionar la exención del 100\% del impuesto territorial. Como puede apreciarse en el numeral 3, I. B) del Cuadro Anexo los "recintos deportivos de carácter particular solo estarán exentos mientras mantengan convenios para el uso gratuito de sus instalaciones deportivas con colegios municipalizados o particulares subvencionados". La disposición agrega que dichos convenios "deberán ser refrendados por la respectiva Dirección Provincial de Educación y establecidos en virtud del Reglamento que para estos efectos fije el Ministerio de Educación y el Instituto Nacional del Deporte". En consecuencia, estamos ante un caso en que el Estado condiciona la entrega de un beneficio -en este caso, una exención tributaria- a la limitación de la propiedad que se tiene sobre un bien.

Los requirentes se enfocaron en impugnar el reglamento que, según dispone la ley, debe regular los contenidos del convenio. De este modo no hay un reclamo de inconstitucionalidad de la condición misma sino que más precisamente del reglamento. Aún así, esgrimen algunos argumentos que podrían ser extensibles. Dicen, por ejemplo, que la norma vulnera el artículo 19 No 21 de la Constitución pues obliga "a poner las instalaciones del club a disposición de un tercero lo que limitaría su posibilidad de emprender nuevas actividades económicas". Agregan que el derecho a emprender se ve truncado "ya que se obliga al ingreso gratuito de terceras personas que impone una saturación del recinto, paralizándose la iniciativa de captar nuevos socios". Concluyen señalando que "de aplicarse la norma impugnada, significaría incrementar las cuotas para cubrir los mayores gastos por mantención, cobertura de destrozos y contratación de seguros, lo que significaría una pérdida de la libertad en el desarrollo de su actividad económica, afectando -de paso- toda autonomía para el cumplimiento de sus propios fines específicos"77. Curiosamente, los requirentes no invocan el derecho de propiedad como uno de aquellos que estaría siendo afectado por la condición.

El Consejo de Defensa del Estado por su parte, argumenta como suele hacerlo el Estado cuando se enfrenta a casos donde la doctrina de las condiciones inconstitucionales es aplicable. Señalan que la posibilidad de acogerse al régimen de exención es facultativa y puede ser ejercida con absoluta libertad. "Es un hecho voluntario, no obligatorio, por lo que no se vulneraría garantía alguna”78.

\footnotetext{
${ }^{76}$ Ley No 20.033, de 2005.

77 Sentencia del Tribunal Constitucional Rol No 759 (2007) p. 12.

${ }^{78}$ Sentencia del Tribunal Constitucional Rol No 759 (2007) p. 13.
} 
Como hemos mencionado, la sentencia no entra a analizar la constitucionalidad de la condición misma pues ella no fue puesta en duda por los requirentes. Analiza en cambio con profundidad la reserva legal en materia tributaria concluyendo que encargar al reglamento la regulación de los convenios es inconstitucional ${ }^{79}$.

A la luz de la doctrina de las condiciones inconstitucionales la constitucionalidad de la disposición comentada pudo haber sido puesta en duda. En efecto, ella condiciona un beneficio a la renuncia a ciertos derechos fundamentales, principalmente la propiedad y el derecho a emprender. En este contexto, es posible que Epstein hubiera impugnado la norma pues obliga a las personas, en este caso agrupadas en una asociación, a negociar con el Estado y con ello exponerse a una limitación en sus derechos. Dado que ello no es admisible, argumentaría Epstein, la condición debiera ser eliminada. Es probable que Kreimer hubiera seguido el mismo camino. En efecto, si analizamos la norma podemos concluir que estamos ante una amenaza y no ante una oferta. Para sostener lo anterior deben invocarse los tres criterios que propone Kreimer. El análisis histórico nos muestra que la situación anterior a la modificación legal concedía la exención sin condición alguna. Desde la perspectiva de la equidad en el trato, la norma está dirigida específicamente a los clubes deportivos privados. Finalmente, el tercer criterio se detiene en analizar qué hubiera hecho el gobierno si no hubiera podido imponer la condición. Es probable que en este caso el gobierno se hubiera desistido de imponer la condición manteniendo vigente, en consecuencia, la exención. Ello por cuanto eliminar la exención a los clubes deportivos con seguridad hubiera afectado la viabilidad económica y subsistencia de muchos de ellos. En este panorama, es poco probable que el gobierno hubiera estado dispuesto a asumir los costos de la desaparición de numerosos clubes deportivos que constituyen importantes áreas verdes en zonas urbanas. Así las cosas, dado que la norma en cuestión se asemeja más a una amenaza que a una verdadera oferta, la condición hubiera sido inconstitucional bajo la mirada de este autor. Finalmente para aventurar lo que hubiera dicho Sullivan se requiere de un análisis más profundo que no es del caso hacer en este documento. Con todo, lo cierto es que, en este caso concreto, el Estado está presionando al receptor de un beneficio con miras a alterar su elección en el ejercicio de alguno de sus derechos. Esto ya es un aspecto que a esta autora hubiera preocupado.

En definitiva, la sentencia presenta un caso donde la aplicación de la doctrina de las condiciones inconstitucionales hubiera sido no solo admisible sino que también bienvenida. Es de esperar que los argumentos sobre los que esta se sustenta vayan extendiéndose para así poder discutir desde nuestro derecho y tradición jurídica este tipo de desafíos que nos presentan las regulaciones actuales.

\subsection{Derechos de Propiedad}

Como hemos visto, la doctrina de las condiciones inconstitucionales se vincula con el derecho de propiedad cuando el Estado subordina un permiso o autorización a

\footnotetext{
79 Sentencia del Tribunal Constitucional Rol No 759 (2007) c. 66 a 91.
} 
una condición que afecta dicho derecho. No hay, en consecuencia, un subsidio o aporte económico estatal en juego.

En nuestro país pueden encontrarse áreas donde los derechos de propiedad se ven en cierta medida debilitados o limitados por la discrecionalidad gubernamental que permite condicionar la entrega de permisos para la disposición o uso del bien sobre el que recae la propiedad. Áreas que presentan interés desde esta perspectiva, y en las que no se profundizará en este trabajo, son la regulación urbana, la medioambiental y la libre competencia, entre otras ${ }^{80}$.

Con todo, esta vez, nos centraremos en una sentencia del Tribunal Constitucional en la que el derecho de propiedad está en juego. Desafortunadamente, no hay un análisis que nos permita señalar, como en el caso anterior, que el Tribunal se está aproximando a la doctrina de las condiciones inconstitucionales. De hecho, a nuestro juicio, tener en cuenta esta doctrina podría haber iluminado el análisis del tribunal y, eventualmente, haber modificado la decisión final.

El decreto supremo No 66 modificó el artículo 2.1.31 de la Ordenanza de Urbanismo y Construcciones estableciendo que en las áreas verdes, definidas como tales en los instrumentos de planificación territorial, solo puede autorizarse "la construcción de edificios de uso público, siempre que el área destinada a estos usos no ocupe más del $20 \%$ de la superficie total del predio destinada a uso área verde". Los senadores recurrentes consideraron que esta disposición contrariaba el artículo 19 No 24 y No 26 de la Constitución pues constituía una "restricción permanente que grava dichas propiedades, lo que quiere decir que el $80 \%$ de la superficie predial no podrá construirse" 81 .

El Tribunal no acogió el requerimiento pues, ante todo, consideró que la disposición impugnada no creaba las áreas verdes sino que únicamente autorizaba, bajo ciertas condiciones, a construir en ellas. De este modo, el Tribunal señaló que la cuestión de fondo -si era o no constitucional prohibir a todo evento la construcción en áreas verdes así declaradas por la autoridad- no era materia de su competencia pues el requerimiento no se refirió -ni pudo referirse- a dicha materia. No pudo referirse porque la disposición que prohibía la construcción en áreas verdes no fue incorporada a la ordenanza por medio del decreto impugnado sino que en un acto anterior cuya inconstitucionalidad no podía alegarse ante el Tribunal Constitucional.

Aún así, es interesante profundizar en el raciocinio que continúa en torno al permiso para construir en áreas verdes pues su análisis nos permite vislumbrar si hay o

\footnotetext{
80 Respecto a la primera, la Ley General de Urbanismo y Construcciones nos presenta más de algún caso. Uno de ellos es la prohibición para modificar una propiedad que se encuentre fuera de la línea de edificación (artículo 5.1.9. de la Ordenanza General de la Ley General de Urbanismo y Construcción). En materia ambiental, por su parte, los Estudios de Impacto Ambiental suelen ser aprobados bajo condición o previa propuesta de medidas de mitigación que, eventualmente, podrían tocar aspectos de la doctrina de las condiciones inconstitucionales (art. 16, 20, 23 y 25 de la Ley de Bases del Medio Ambiente). Finalmente, lo mismo ocurre con las decisiones del Tribunal de la Libre Competencia que pude someter las contiendas sometidas a su conocimientos a condiciones u otras medidas de mitigación que afectan el derecho de propiedad (artículo 18, No 2 y 31 del Decreto Ley 211 sobre Libre Competencia).

81 Sentencia del Tribunal Constitucional, Rol No 373 (2003) p. 2.
} 
no espacio para una futura doctrina de las condiciones inconstitucionales. Dice el Tribunal que:

"La norma nada impone, obliga o exige con respecto a la situación anterior sino, muy por el contrario, autoriza o permite que en estos predios pueda hacerse algo que antes de su entrada en vigor estaba prohibido, cual es realizar las construcciones que el precepto señala, sujetas a las regulaciones que el mismo establece. En consecuencia, la disposición en estudio lejos de limitar el dominio sobre un predio destinado a área verde que no se haya materializado, está permitiendo realizar tales construcciones en los términos prefijados por ella, siempre y cuando el titular del dominio de ese tipo de predio, en forma voluntaria y conforme a su personal conveniencia, resuelva hacerlo" 82 .

Como puede apreciarse, la figura que analiza el Tribunal es similar a aquellas usadas para ejemplificar la doctrina de las condiciones inconstitucionales. En efecto, el decreto en cuestión no está obligando ni induciendo al propietario del terreno calificado como área verde a construir. Simplemente está señalando que, en caso de optar libremente por hacerlo, dicha construcción no puede ocupar más de $20 \%$ de la superficie total del predio. Del mismo modo, la autorización de la autoridad urbana en Estados Unidos, no obligaba a los Nollan ni a la Sra. Dolan a construir. Simplemente, les exigía que, de hacerlo, debían cumplir ciertas condiciones.

El Tribunal no se adentra en dilucidar si esta condición es justa, razonable o constitucional. En otras palabras, no despierta preocupación el hecho que, en virtud de la condición, no pueda utilizarse un $80 \%$ del bien sobre el cual recae la propiedad. Se entiende que el Tribunal no podía pronunciarse sobre el artículo que autorizaba a declarar áreas verdes y prohibía la construcción en ellas, pues este no era motivo de controversia. Pero eso no era argumento suficiente para dejar de pronunciarse sobre la condición misma, impuesta a quienes decidieran libremente construir. Cabe destacar, que en nuestros ejemplos de Estados Unidos, la Corte Suprema tampoco se detiene a analizar si era o no constitucional la facultad de la autoridad de negar la ampliación de la casa de veraneo de los Nollan o del local de la Sra. Dolan. A pesar de ello, sí entran -como sabemos- a analizar la condición misma impuesta por dicha autoridad.

Como vimos, la doctrina del país del norte, ante un caso como este, hubiera requerido un nexo esencial entre la limitación al dominio y el objetivo de aquella limitación, además de haber realizado un análisis de proporcionalidad. Nada similar se hizo en este caso pues, a juicio del Tribunal, lo importante no era la condición sino que el permiso para realizar construcciones en el predio en los términos prefijados por la ordenanza. El hecho que se ampliara el campo de libertad del propietario fue suficiente para liberar de todo vicio constitucional a la norma sin importar si esta ampliación estaba siendo condicionada en términos proporcionales o razonables.

82 Sentencia del Tribunal Constitucional, Rol No 373 (2003) c. 38. 
En definitiva, el caso sienta un primer antecedente donde, si bien era posible aplicar los fundamentos de la doctrina de las condiciones inconstitucionales, estos no fueron invocados.

\section{CONCLUSIÓN}

En las primeras páginas de este trabajo se analizó la evolución histórica de la doctrina de las condiciones inconstitucionales desde sus inicios y se expusieron algunos casos que la academia estadounidense suele citar al referirse al tema. Como se vio, en virtud de esta doctrina no sería constitucional que el Estado exija la renuncia a derechos fundamentales como requisito para recibir algún subsidio o permiso. Con todo, también se dijo que ni la Corte Suprema de Estados Unidos ni la academia de ese mismo país han logrado elaborar una convincente aplicación de la doctrina a los casos en que esta es aplicable. De hecho, de seguir las opiniones de algunos autores, es posible que ello no sea una meta alcanzable por diversas circunstancias planteadas por los críticos de la doctrina. Más allá de lo anterior, lo interesante es que los fundamentos de la doctrina de las condiciones inconstitucionales se presentan como una interesante limitación al poder discrecional del Estado que, en este caso, se manifiesta a través del reparto de dineros públicos o de las autorizaciones que deben solicitar los individuos en ciertas circunstancias. La evolución de la doctrina en la jurisprudencia futura es un tema aún incierto. Lo valioso, y lo que se ha querido destacar, es lo que se ha alcanzado hasta hoy en la jurisprudencia de Estados Unidos.

En la segunda parte de este trabajo se analiza la posible aplicación de la doctrina de las condiciones inconstitucionales en Chile. Para ello nos detenemos en la garantía constitucional contenida en el artículo 19 No 26 y en la jurisprudencia del Tribunal Constitucional que le ha ido dando forma pues es en este numeral donde la doctrina de las condiciones inconstitucionales encuentra fundamentos en nuestro derecho. Luego, a través de diversas sentencias de la Corte Constitucional, se indaga en tres áreas específicas: educación, derechos de propiedad y condicionamiento de las exenciones tributarias. Todos los casos elegidos se construyen sobre fundamentos similares a los que sirven de sustento a la doctrina de las condiciones inconstitucionales en Estados Unidos. En algunos de ellos, como se vio, la cercanía con la doctrina que se ha expuesto es manifiesta mientras que en otros el Tribunal no se detiene mayormente en los aspectos relevantes para este trabajo.

En definitiva, con estos primeros antecedentes, consideramos no solo viable sino que también tremendamente necesario iniciar un diálogo de interesantes perspectivas que tiene como partes a una doctrina nacida al alero de una tradición jurídica extranjera y a un sistema como el nuestro donde los fundamentos de dicha doctrina son hoy visibles. Solo resta que el Tribunal Constitucional transforme estos fundamentos presentes en nuestro marco constitucional y en algunos de sus fallos en un precedente sólido y sistemático que permita dar una nueva perspectiva al análisis de los conflictos constitucionales entre el Estado y los individuos. 


\section{BIBLIOGRAFÍA CITADA}

ArósticA, Iván (2001): Derecho Administrativo Económico (Santiago, Ediciones Universidad Santo Tomás) $181 \mathrm{pp}$.

Avilés, Víctor Manuel (2008): "Sentencias del Tribunal Constitucional con Alcances Tributarios”, en: Fermandois, Arturo (edit.), Sentencias Destacadas 2007 (Santiago, Libertad y Desarrollo).

Berkowitz, Daniel, Pistor, Katrina y Richard, Jean Francois (2003): “The Transplant Effect”, 51 Am. J. Comp. L. 163.

Bertelsen, Raúl (2005): "Libertad de Enseñanza: Dos Sentencias del Tribunal Constitucional”, en: Fermandois, Arturo (edit.), Sentencias Destacadas 2004 (Santiago, Libertad y Desarrollo).

Callies, David L. (1999): "Regulatory Takings and The Supreme Court: How Perspectives on Property Rights have changed from Penn Central to Dolan, and What State and Federal Courts are Doing about it", 28 Stetson L. Rev. 523.

CEA, José Luis (2004): Derecho Constitucional Chileno (Santiago, Ediciones Universidad Católica, Tomo II).

Comisión de Educación, Cultura, Ciencia y Tecnología del Senado (2007): Primer Informe Complementario recaído en el Proyecto de Ley que Establece una Subvención Preferencial para Niños Socioeconómica Vulnerables. Boletín 4030-04.

DelaVeaU, Rodrigo (2006): "La Regulación Expropiatoria en la Jurisprudencia Americana", Revista Chilena de Derecho, vol. 33 No 3: pp.411-438.

EPSTEIN, Richard (1993): Bargaining with the State (Princeton University Press) 338 pp.

Epstein, Richard (1988): "The Supreme Court 1987 Term: Unconstitutional Conditions, State Power, and Limits of Consent", 102 Harv. L. Rev. 5.

EPSTEIN, Richard (1989): "Unconstitutional Conditions and Bargaining Breakdown", 26 San Diego L. Rev. 189.

Evans De la Cuadra, Enrique (1999): Los Derechos Constitucionales (Santiago, Editorial Jurídica, Tomo II).

FArber, Daniel, Eskridge, William y FrICKeY, Philip (2003): Constitutional Law Themes for the Constitution's Third Century (Thomson West) 1256 pp.

Fermandois, Arturo (2001): "El Principio de Reserva Legal como Garantía Sustantiva" Revista Chilena de Derecho, vol. 28 No 2: pp. 287-298.

FERnÁndeZ, Miguel Ángel (2006): Los Derechos Fundamentales en 25 Años de Jurisprudencia del Tribunal Constitucional, Cuadernos del Tribunal Constitucional No 33.

FudenberG, Brooks (1995-1996): "Unconstitutional Conditions and Greater Powers: A Separability Approach”, 43 UCLA L. Rev. 371.

Hale, Robert (1935): "Unconstitutional Conditions and Constitutional Rights", 35 Colum. L. Rev. 321.

HAYEK, Friedrich (2006): Derecho, Legislación y Libertad (Madrid, Unión Editorial).

KrEIMER, Seth F. (1984): "Allocational Sanctions: The Problem of Negative Rights in a Positive State”, 132 U. Pa. L. Rev. 1293. 
LEGRAND, Pierre (1997): “The Impossibility of 'Legal Transplants", 4 Maastricht Journal of European and Comparative Law 111.

MASSEY, Calvin (2005): American Constitutional Law, Powers and Liberties (ASPEN Publishers) 1235 pp.

Mazzone, Jason (2002-2003): “The Waiver Paradox”, 97 Nw. U. L. Rev. 801.

Merrill, Maurice H. (1929): "Unconstitutional Conditions", 77 U. Pa. L. Rev. 879.

Ministerio Secretaría General de la Presidencia (2000): Doctrina Constitucional del Presidente Eduardo Frei Ruiz-Tagle (División Jurídica Legislativa).

Proyecto de Ley que Establece una Subvención Preferencial para Niños y Niñas Socioeconómicamente Vulnerables. Boletín 4030-04.

RaWlings, Laura B. y Rubio, Gloria M. (2003): "Evaluating the Impact of Conditional Cash Transfer Programs, Lessons from Latin America” (World Bank Policy Research Working Paper 3119).

RosenkrantZ, Carlos F. (2003): "Against Borrowings and other Non authoritative Uses of Foreign Law", International Journal of Constitutional Law 1 No 2, 269.

SCHAUER, Frederick (1994-1995): "Too Hard: Unconstitutional Conditions and the Chimera of Constitutional Consistency", 72 Denv. U. L. Rev. 989.

Soто, Sebastián (2005): "Requerimiento en Proyecto de Ley Sobre Jornada Escolar Completa: Una Mirada desde los Incentivos”, Ius Publicum 15, 269.

Stone, Geoffrey; Seidman, Louis Michael; Sunstein, Cass; Tushnet, Mark y KarLAN, Pamela (2005): Constitutional Law (ASPEN Publishers).

Sullivan, Kathleen (1989): "Unconstitutional Conditions”, 102 Harv. L. Rev. 1415.

Sullivan, Kathleen y GunTHer, Gerald (2004): Constitutional Law (Foundation Press).

Sunstein, Cass (1989): "Is There an Unconstitutional Conditions Doctrine?” 26 San Diego L. Rev. 337.

Sunstein, Cass (1990): "Why the Unconstitutional Condition Doctrine is an Anachronism? (With Particular Reference to Religion, Speech and Abortion)" 70 B.U.L. 593.

VARAS, Paulino y Salvador MOHOR (1997): "Acerca de la Esencia de los Derechos Constitucionales y de su Libre Ejercicio que Consagra el Artículo 19 No 26 de la Constitución Política", Revista de Derecho de la Universidad Católica de Valparaíso, XVIII, 1997.

ViVANCO, Ángela (2007): "Derecho a la Educación y Libertad de Enseñanza: un Aparente Conflicto y sus Efectos sobre una Proposición Normativa en Chile”, Temas de la Agenda Pública, año 2, No 8, agosto 2007.

Watson, Alan (2006): "Legal Transplants and European Private Law". Disponible en: $<$ http://www.alanwatson.org/legal_transplants.pdf> [Fecha de consulta: 1 de septiembre de 2008].

\section{JURISPRUDENCIA CITADA}

Dolan v. City of Tigard, 512 U.S. 374 (1994)

FCC v. League of Woman Voters of Cal., 468 U.S. 364 (1984).

Frost \& Frost Trucking Co. v. Railroad Commission, 271 U.S. 583 (1926) 
Gonzales v. Carhart et al., 18 de abril, 2007

Insurance Company v. Morse, 87 U.S. 445 (1874)

Legal Services Corp. v. Velázquez, 531 U.S. 533 (2001).

McAuliffe v. Mayor of New Bedford, 155 Mass. 216, 220, 29 N.E. 517, 518 (1892)

Nollan et ux v. California Coastal Commission, 483 U.S. 825 (1987)

Pennsylvania Coal Company v. Mahon, 260 US 393 (1922)

Rust v. Sullivan, 500 U.S. 173 (1991)

Sentencia del Tribunal Constitucional Español 77/1985.

Sentencia del Tribunal Constitucional Rol No 43, 24 de febrero de 1987.

Sentencia del Tribunal Constitucional Rol No 200, 14 de diciembre de 1994.

Sentencia del Tribunal Constitucional Rol No 226, 30 de octubre de 1995.

Sentencia del Tribunal Constitucional Rol No 280, 20 de octubre de 1998.

Sentencia del Tribunal Constitucional Rol No 373, 22 de julio de 2003.

Sentencia del Tribunal Constitucional Rol No 410, 14 de junio de 2004.

Sentencia del Tribunal Constitucional Rol No 468, 09 de diciembre de 2006.

Sentencia del Tribunal Constitucional Rol No 513, 02 de enero de 2007.

Sentencia del Tribunal Constitucional Rol No 541, 26 de diciembre de 2006.

Sentencia del Tribunal Constitucional Rol No 546, 17 de noviembre de 2006.

Sentencia del Tribunal Constitucional Rol No 559, 07 de junio de 2007.

Sentencia del Tribunal Constitucional Rol No 718, 26 de noviembre de 2007.

Sentencia del Tribunal Constitucional Rol No 759, 26 de noviembre de 2007.

Sentencia del Tribunal Constitucional Rol No 773, 26 de noviembre de 2007.

Sentencia del Tribunal Constitucional Rol No 781, 27 de septiembre de 2007.

Sentencia del Tribunal Constitucional Rol No 792, 03 de enero de 2008.

Sentencia del Tribunal Constitucional Rol No 1022, 23 de enero de 2008.

South Dakota v. Dole, 483 U.S. 203 (1987).

United States v. American Library Association, 539 U.S. 194 (2003)

United States v. Butler, 297 U.S. 1 (1936).

Western Union Telegraph Co. v. Kansas, 216 U.S. 1, 53 (1909)

\section{NORMAS CITADAS}

Ley No 20.248, Establece Ley de Subvención Escolar Preferencial. Diario Oficial, 1 de febrero de 2008.

Ley No 20.033, Modifica la Ley número 17.235, sobre Impuesto Territorial; el decreto Ley número 3.063, sobre Rentas Municipales; la Ley número 18.695, Orgánica Constitucional de Municipalidades, y faculta a las municipalidades para otorgar condonaciones que indica. Diario Oficial, 1 de julio de 2005.

Ley No 19.979, Modifica el Régimen de Jornada Escolar Completa Diurna y otros cuerpos legales. Diario Oficial, 6 de noviembre de 2004. 
